\title{
Effect of Heat Treatments on Hydrogen Environment Embrittlement of Alloy 718
}

\author{
Seiji FUKUYAMA and Kiyoshi YOKOGAWA \\ Chugoku National Industrial Research Institute, AIST, MITI, Japan \\ 2-2-2 Hiro-Suchiro, Kure, Hiroshima, 737-01, Japan
}

\begin{abstract}
Tensile property and fatigue crack growth of Alloy 718, which was solution-annealed at 1223 $1323 \mathrm{~K}$ and aged, were investigated in high-pressure hydrogen of 1.1 MPa up to 19.7 MPa and argon at room temperature up to $773 \mathrm{~K}$. The effect of gaseous inhibitors added to hydrogen atmosphere on the fatiguc crack growth was also investigated to prevent hydrogen assistcd fatigue crack growth. Hydrogen environment embrittlement (HEE) incrcased with increasing $\delta$ phase and with decreasing testing temperature. HEE still occurred at $773 \mathrm{~K}$. Delayed fracture was found predominantly in fatigue crack growth in hydrogen. The crack initiation occurred at carbide, then the crack propagated along the interface between $\delta$ phasc and $\gamma$ matrix of the alloy with $\delta$ phase or along the grain boundary of the alloy without $\delta$ phase. It was observed that oxygen or carbon monoxide added to hydrogen atmosphere had much effect to prevent hydrogen assisted fatigue crack growth.
\end{abstract}

\footnotetext{
Superalloys $718,625,706$ and Various Derivatives Edited by E.A. Loria

The Minerals, Metals \& Materials Society, 1994
} 


\section{Introduction}

Alloy 718 of Ni-base superalloy which is superior to the resistance to high temperature has been used for the main construction materials of the hydrogen fueled rocket engine of $\mathrm{H}-\Pi$ rocket, LE- $7^{1}$ engine, developed by National Space Development Agency of Japan (NASDA). As the alloy is exposed to hydrogen in the engine, hydrogen environment embrittlement (HEE) could be the important problem for the alloy.

The effects of hydrogen on mechanical propertics of the alloy were mainly investigated when National Acronautics and Space Administration (NASA) developed the Space Shuttle Main Engine (SSME). The mechanical tests of Alloy 718 in high pressure hydrogen have been carried out by Harris, Jr. et al. ${ }^{2)}$ in Pratt and Whitney Aircraft and Walter et al. ${ }^{33}$ in Rocketdyne Division which manufactured SSME. Furthermore Rie et al. ${ }^{t)}$ carried out low cycle fatigue tests of Alloy 718 in high pressure hydrogen. However the effect of metallic structure on HEE of the alloy has not been clear yet.

In the present paper, tensile tests and fatigue crack growth tests of the alloy were carried out in high pressure hydrogen of $1.1 \mathrm{MPa}$ up to $19.7 \mathrm{MPa}$ and argon at room temperature up to 773 $K$. The effect of the heat treatment on HEE of the alloy was discussed. The effect of inhibitive gas added to hydrogen atmosphere to prevent hydrogen assisted fatigue growth was also discussed.

\section{Material}

\section{Experimental Procedure}

The materials used were Alloy 718 whose chemical compositions in wt \% are shown in Table I. These materials were casted, hot forged and treated with the following heat treatment. The material was solution-annealed at the temperature range from $1223 \mathrm{~K}$ up to $1333 \mathrm{~K}$ for $3.6 \mathrm{ks}$, and then oil-quenched. The annealed materials were aged at $991 \mathrm{~K}$ for $28.8 \mathrm{ks}$, cooled at a rate of $1.5 \times 10^{-2} \mathrm{~K} / \mathrm{s}$, aged at $894 \mathrm{~K}$ for $36.0 \mathrm{ks}$ to precipitate $\gamma^{\prime}$ and $\gamma^{\prime \prime}$, and then cooled in air. Metallographic structure of the heat treated alloy by using a scanning electron microscope are shown in Fig. 1. Microstructures of the alloy solution-annealed at $1233 \mathrm{~K}$ consisted of the large carbide particles of precipitate (A), continuous $\delta$ phase (B), a needle-shaped precipitate of $\delta$ phase in the Widmanstaetten pattern (C) and a matrix. Precipitates of $\gamma^{\prime}$ and $\gamma^{\prime \prime}$ were formed throughout the structure during the aging treatment and were not observed at the magnifications used, however the matrix consisted of $\gamma, \gamma^{\prime}$ and $\gamma^{\prime \prime}$ characterized by using transmission electron microscope. Furthermore, microstructure of the alloy solution-annealed at $1323 \mathrm{~K}$ consisted of the large carbide (A) and a matrix.

Table I Chemical compositions of Alloy 718

\begin{tabular}{|c|c|c|c|c|c|c|c|c|c|c|c|c|c|c|c|}
\hline Materials & C & Si & Mn & P & S & Ni & Cr & Mo & Co & Al & Ti & Ca & Fe & B & Cb+T/2 \\
\hline Alloy(A) & 0.03 & 0.06 & 0.16 & 0.002 & 0.001 & 51.95 & 18.76 & 3.02 & 0.06 & 0.42 & 1.02 & 0.02 & Rem. & 0.006 & 5.06 \\
\hline Alloy(B) & 0.05 & 0.05 & 0.13 & 0.005 & 0.005 & 52.00 & 18.89 & 3.04 & 0.05 & 0.48 & 1.15 & 0.05 & Rem. & 0.004 & 5.32 \\
\hline
\end{tabular}

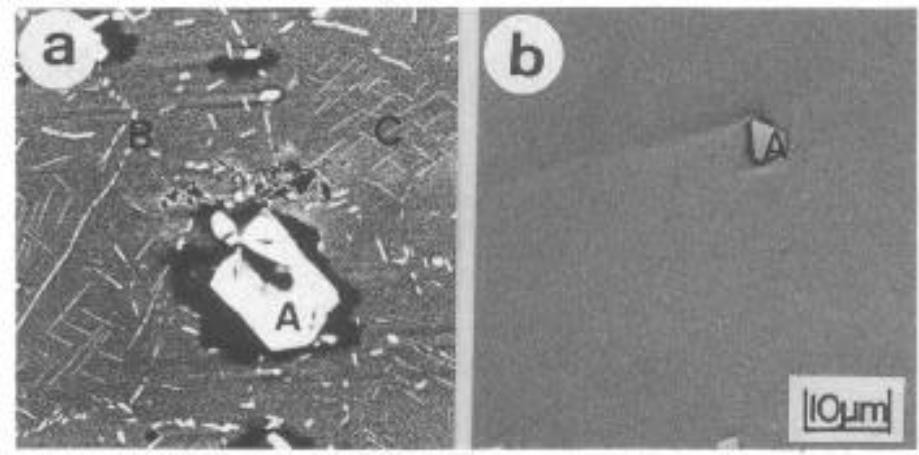

Fig.1 Metallographic structures of Alloy 718.

(a):Solution-annealed at $1243 \mathrm{~K}$ (A:Nb-Ti carbide, B: $\delta$ phase, $\mathrm{C}: \delta$ phase of Widmanstaetten structure.), (b): Solution-annealed at $1323 \mathrm{~K}$ (A:Nb-Ti carbide.) 


\section{Tensile Testing}

Cylindrical tensile specimens with a gauge section of $20 \mathrm{~mm}$ long and $4 \mathrm{~mm}$ in diameter were machined from the heat treated materials (A). The surface of the specimens were polished with $0.05 \mu \mathrm{m} \gamma-\mathrm{Al}_{2} \mathrm{O}_{3}$ dispersed on microcloth and washed in an acetone bath. Tensile tests werc conducted with a strain rate of $4.17 \times 10^{-5} \mathrm{~s}^{-1}$ by using a specially designed apparatus ${ }^{5)}$. The tests were conducted in 1.1 MPa argon of $99.99 \%$ and $19.7 \mathrm{MPa}$ hydrogen of $99.9999 \%$ purity. The tests were performed at $293 \mathrm{~K}$ up to $773 \mathrm{~K}$.

\section{Fatigue Crack Growth Testing}

DCB type specimens with $107 \mathrm{~mm}$ in width and $10 \mathrm{~mm}$ in thickness were machined from the heat treated materials (B). The fatigue crack growth tests were conducted in 1.1 MPa argon, and 1.1 MPa and 19.7 MPa hydrogen by using a specially designed fatigue testing apparatus ${ }^{6,7}$ under the conditions of sinusoidal tension-tension cycle from 0.01 to $10 \mathrm{~Hz}$ with a stress ratio $\mathrm{R}=0.1$. Crack length was monitored by means of the AC electric-potential technique. All tests werc performed at $293 \pm 1 \mathrm{~K}$. K of the DCB type of specimen was calculated by the following equation:

$$
\mathrm{K}=\left(\mathbf{P} / \mathrm{H}(\mathbf{a})^{1 / 2}\right)(\mathbf{a} / \mathrm{H}(\mathbf{a})+0.7) \cdot \mathrm{f}(\mathbf{m})^{8)}
$$

where $\mathbf{P}$ is the load per unit effective thickness ${ }^{9)}$, $\mathbf{a}$ is the crack length, $\mathrm{H}(\mathbf{a})$ is the beam height at $\mathbf{a}, \mathbf{m}$ is the gradient of the beam, and $f(\mathbf{m})$ is a constant of 2.98 in this case.

\section{Gaseous Inhibitors}

The fatigue crack growth tests were also conducted in $1.1 \mathrm{MPa}$ hydrogen gas containing gaseous inhibitors. The kinds of gaseous inhibitors tested and the concentration in pure hydrogen gas $(99.9999 \%)$ were as follows; oxygen $(0.19 \%)$, carbon monoxide $(0.99 \%)$, carbon dioxide $(1.01 \%)$ or water vapor $(0.03 \%)$. The hydrogen containing each inhibitor was provided by the gas supplier. All tests were performed at $293 \pm 1 \mathrm{~K}$.

\section{Tensile Properties}

\section{Results and Discussion}

Effect of Temperature of Solution Treatment. The effect of tempcraturc of the solution treatment on the tensile properties of the alloy in 1.1 MPa argon and 19.7 MPa hydrogen is shown in Fig.2. $0.2 \%$ proof stress (PS) and ultimate tensile strength (UTS) both in argon and hydrogen decrcased, and elongation and reduction of arca increased with increasing temperature of the solution treatment. Elongation and reduction of area were almost constant above $1273 \mathrm{~K}$. Hydrogen showed marked effect on UTS and ductility. UTS, elongation and reduction of area in hydrogen were smaller than those in argon. UTS, elongation and reduction of area of the alloy for the solution-annealed at $1233 \mathrm{~K}$ in hydrogen was $98 \%, 33 \%$ and $31 \%$ of that in argon respectively. Whilc in hydrogen UTS, elongation and reduction of area of the alloy solution-annealed at $1323 \mathrm{~K}$ was $100 \%, 41 \%$ and $47 \%$ of that in argon respectively. The effect of hydrogen on UTS, elongation and reduction of area increased with decreasing temperature of the solution treatment, so that the effect of hydrogen on the ensile properties increased with increasing $\delta$ phase. However hydrogen shows no effect on PS.

Fracture surfaces of the alloy fractured in $19.7 \mathrm{MPa}$ hydrogen at room temperature are shown in Fig.3. The crack initiation occurred at carbide. Intergranular fracture and brittle transgranular fracture were observed on the fracture surface of the alloy without $\delta$ phase. The brittlc transgranular fracture along the interface between $\delta$ phase and $\gamma$ matrix were mainly observed on the fracture surface of the alloy with $\delta$ phase. Dimple rupture were mainly observed on the fracture surface of the alloy both with and without $\delta$ phase in argon. Dimple size of the alloy without $\delta$ phase was smaller than that with $\delta$ phase.

Effect of Testing Temperature. The effect of testing temperature on HEE of the alloy solution-annealed at $1323 \mathrm{~K}$ (without $\delta$ phase) is shown in Fig.4. PS and UTS in argon decreased with increasing temperature, and elongation and reduction of area were almost constant independently of temperature. While PS and UTS in hydrogen decreased with 
increasing temperature, however elongation and reduction of area increased with increasing temperature.

It is found that HEE still occurred at $773 \mathrm{~K}$. The effect of testing temperature on tensile properties of the alloy with $\delta$ phase both in argon and hydrogen showed similar tendency of the alloy without $\delta$ phase. The effect of testing temperature on HEE of the alloy with $\delta$ phase also showed similar tendency of the alloy without $\delta$ phase.

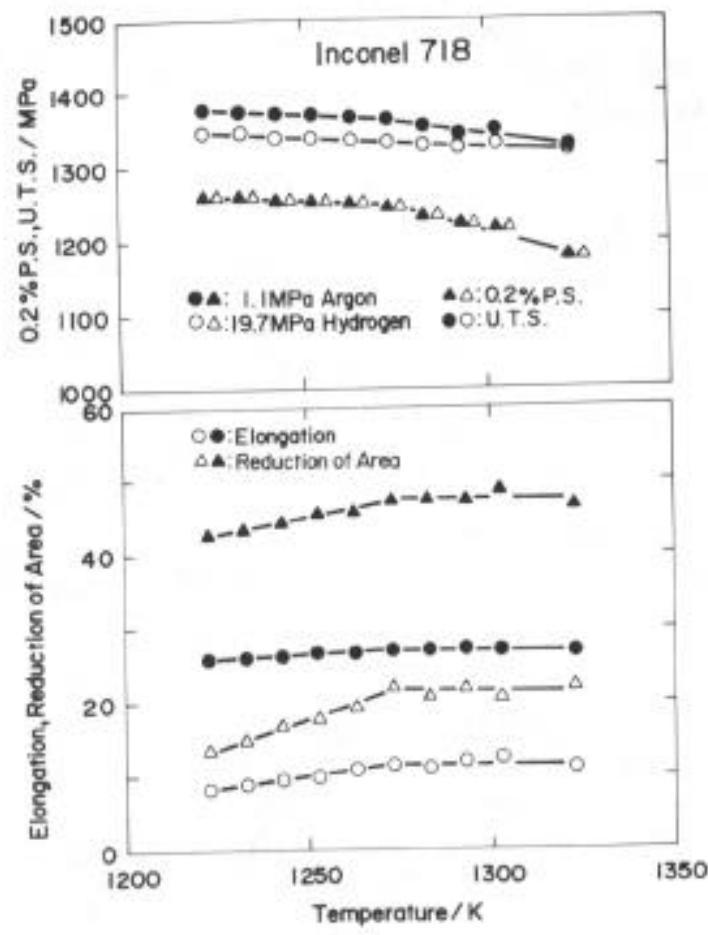

Fig.2 Effect of temperature of solution treatment on tensile propertics of Alloy 718 in 1.1 MPa argon and $19.7 \mathrm{MPa}$ hydrogen at $293 \mathrm{~K}$.

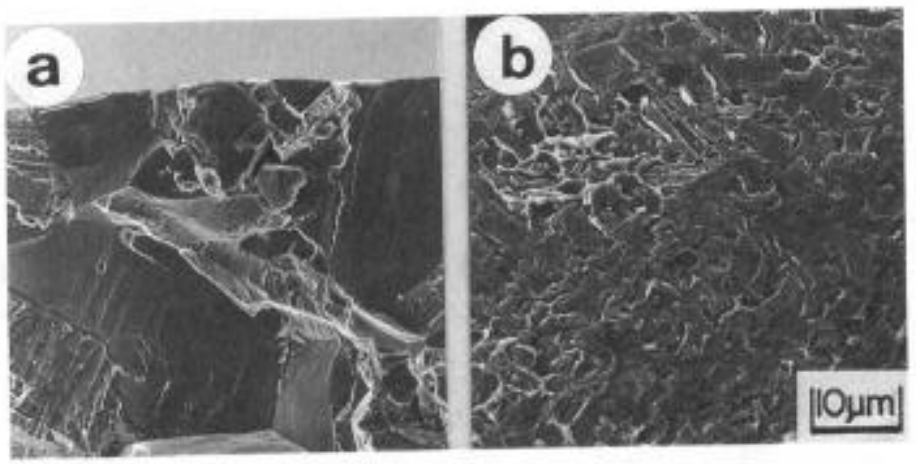

Fig.3 Fracture surfaces of Alloy 718 fractured in $19.7 \mathrm{MPa}$ hydrogen at $293 \mathrm{~K}$.

(a) : without $\delta$ phase, (b) : with $\delta$ phase

Dimple rupture was mainly observed on the fracture surface of the alloy both with and without $\delta$ phase in argon at elevated temperatures. While the step like pattern was mainly observed on the fracture surface of the alloy both with and without $\delta$ phase in hydrogen at elevated temperatures. The step like pattern of the alloy with $\delta$ phase in $19.7 \mathrm{MPa}$ at $573 \mathrm{~K}$ is shown in Fig. 5 .

Fatigue Crack Growth

Effect of $\Delta \mathbf{K}$. The effect of stress intensity factor range $(\Delta \mathrm{K})$ on fatigue crack growth rate $(\mathrm{da} / \mathrm{dN}$ ) of the alloys is shown in Fig.6. The alloy solution-annealed at $1323 \mathrm{~K}$ (without $\delta$ 
phase) and that solution-annealed at $1243 \mathrm{~K}$ (with $\delta$ phase) were used in the figure. da/dN of all the alloys increased with increasing $\Delta \mathrm{K}$. Hydrogen showed significant effect on $\mathrm{da} / \mathrm{dN}$ of the alloy with $\delta$ phase above $\Delta \mathrm{K}$ of $35 \mathrm{MPa} \cdot \mathrm{m}^{1 / 2}$. da/dN in hydrogen was higher than that in argon, i.c. da/dN in argon was $1.8 \times 10^{-7} \mathrm{~m} /$ cycle at $\Delta \mathrm{K}$ of $50 \mathrm{MPa} \mathrm{m}^{1 / 2}$, while that in hydrogen was $2.7 \times 10^{-} \mathrm{m} / \mathrm{cycle}$, so that $\mathrm{da} / \mathrm{dN}$ in hydrogen is 1.5 times higher than that in argon. However hydrogen showed little effect on da/dN below $\Delta \mathrm{K}$ of $35 \mathrm{MPa}^{*} \mathrm{~m}^{1 / 2}$.

Hydrogen showed a little effect on da/dN of the alloy without $\delta$ phase. $\mathrm{da} / \mathrm{dN}$ of the alloy with $\delta$ phase was higher than that of the alloy without $\delta$ phase, so that fatigue crack growth increases by $\delta$ phase both in argon and hydrogen, and the effect of hydrogen on $\mathrm{da} / \mathrm{dN}$ increases by $\delta$ phase.

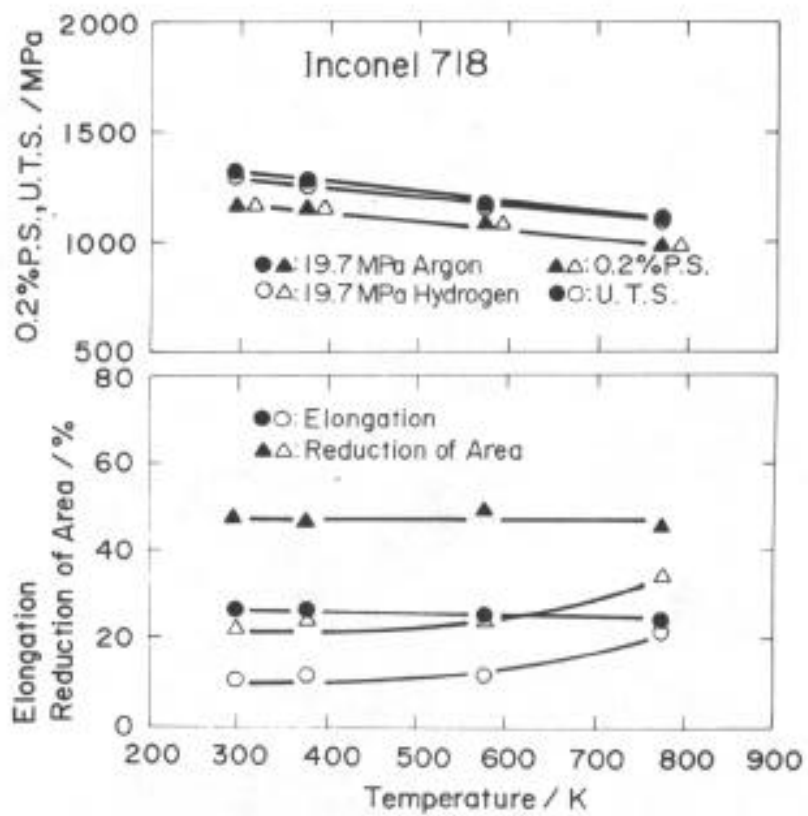

Fig.4 Effect of testing temperature on hydrogen environment embrittlement of Alloy 718 without $\delta$ phase.

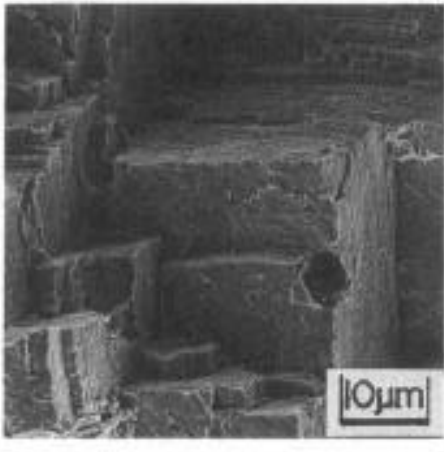

Fig.5 Fracture surface of Alloy 718 with $\delta$ phase fractured in $19.7 \mathrm{MPa}$ hydrogen at $573 \mathrm{~K}$.

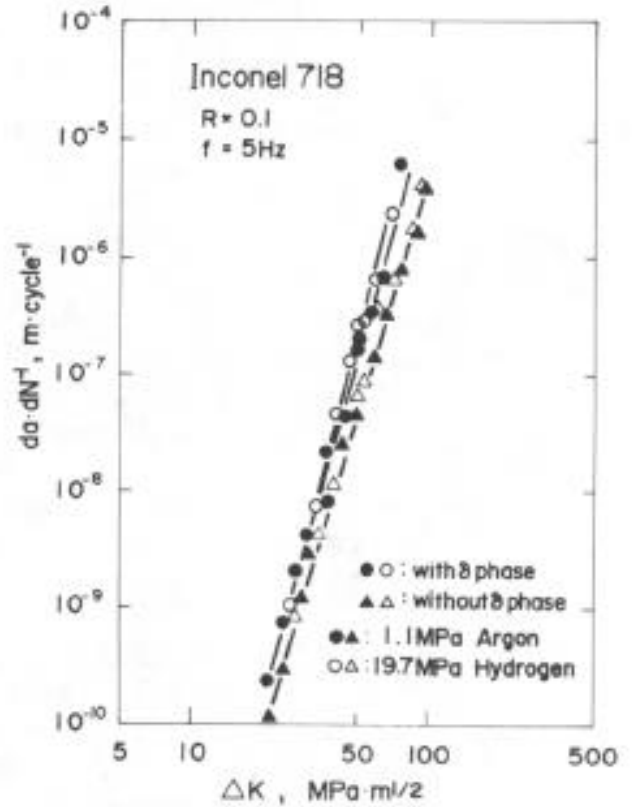

Fig. 6 Effect of $\Delta \mathrm{K}$ on da/dN of Alloy 718 in 1.1 $\mathrm{MPa}$ argon and 19.7 MPa hydrogen at $293 \mathrm{~K}$. 
Effect of Frequency. The effect of $\mathbf{f}$ on $\mathrm{da} / \mathrm{dN}$ of the alloy without $\delta$ phase is shown in Fig. 7. $\mathrm{da} / \mathrm{dN}$ in argon was almost constant, while that in hydrogen increased with decreasing f and with increasing hydrogen pressure. $\mathrm{da} / \mathrm{dN}$ in $19.7 \mathrm{MPa}$ hydrogen at $\mathbf{f}=1 \mathrm{~Hz}$ is 1.3 times higher than that in argon, while that at $\mathbf{f}=0.1 \mathrm{~Hz}$ is 3.7 times higher and that at $\mathbf{f}=0.01 \mathrm{~Hz}$ is 23 times higher, so that the effect of hydrogen on $\mathrm{da} / \mathrm{dN}$ increases with decreasing $\mathbf{f}$.

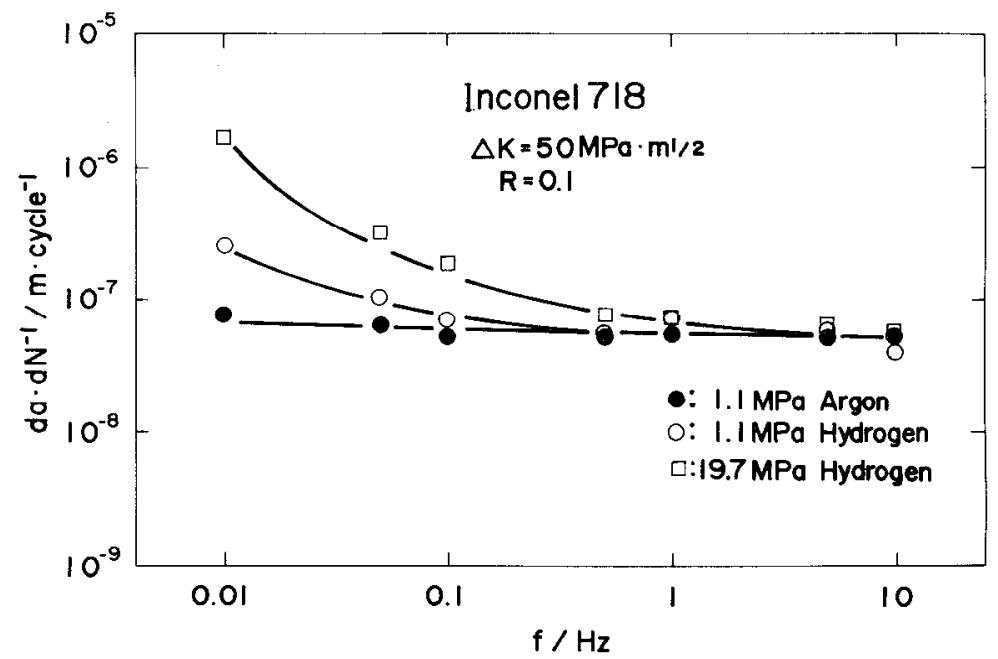

Fig.7 Effect of $\mathbf{f}$ on da/dN of Alloy 718 without $\delta$ phase in 1.1 $\mathrm{MPa}$ argon, and 1.1 and $19.7 \mathrm{MPa}$ hydrogen.

It is proposed by Wei et al. ${ }^{10)}$ that the rate of fatigue crack growth in an aggressive environment, $(\mathrm{da} / \mathrm{dN}) \mathrm{e}$, is composed of the sum of three components,

$$
(\mathrm{da} / \mathrm{dN}) \mathrm{e}=(\mathrm{da} / \mathrm{dN}) \mathrm{r}+(\mathrm{da} / \mathrm{dN}) \mathrm{cf}+(\mathrm{da} / \mathrm{dN}) \mathrm{scc}
$$

where $(\mathrm{da} / \mathrm{dN}) \mathrm{r}$ is the rate of fatigue crack growth in an inert environment, $(\mathrm{da} / \mathrm{dN}) \mathrm{scc}$ is the contribution by sustained-load crack growth at $K$ levels above $K{ }$ and (da/dN)cf represents a cycle-dependent contribution requiring synergistic interaction of fatigue and environmental attack. In the model, $(\mathrm{da} / \mathrm{dN}) \mathrm{scc}$ depends on time.

$$
\begin{aligned}
& (\mathrm{da} / \mathrm{dN}) \mathrm{e}=(\mathrm{da} / \mathrm{dN}) \mathrm{r}+(\mathrm{da} / \mathrm{dN}) \mathrm{cf}+\int \mathrm{\tau}(\mathrm{da} / \mathrm{dt}) \operatorname{scc} \mathrm{dt} \\
& (\mathrm{da} / \mathrm{dt}) \mathrm{e}=\mathbf{f}[(\mathrm{da} / \mathrm{dN}) \mathrm{r}+(\mathrm{da} / \mathrm{dN}) \mathrm{cf}]+(\mathrm{da} / \mathrm{dt}) \mathrm{scc}
\end{aligned}
$$

The effect of $\mathbf{f}$ on da/dt of the alloy without $\delta$ phase is shown in Fig. 8 . da/dt in argon decteased with decreasing $\mathbf{f}$. While da/dt in $19.9 \mathrm{MPa}$ hydrogen decreased with decreasing $\mathbf{f}$ down to $0.5 \mathrm{~Hz}$ and that in $1.1 \mathrm{MPa}$ hydrogen decreased with decreasing $\mathbf{f}$ down to $0.1 \mathrm{~Hz}$, and then were almost constant. These results showed that delayed fracture was predominantly in fatigue crack growth in hydrogen at lower $\mathbf{f}$.

Walter et al. ${ }^{3)}$ studied the fatigue crack growth of Alloy 718 . The metallic structure of the alloy consisted of the carbides and $\gamma$ matrix only. Fatigue crack growth test was conducted in hydrogen up to $68.9 \mathrm{MPa}$ under the conditions of tension-tension cycle from 0.1 to $1 \mathrm{~Hz}$ with a strcss ratio $\mathrm{R}=0.1$. $\mathrm{da} / \mathrm{dN}$ in hydrogen was higher than that in helium in their results. They also studied the effect of $\mathbf{f}$ on da/dN under the condition of $\mathbf{f}$ from 0.1 to $1 \mathrm{~Hz}$ under $\Delta \mathrm{K}$ of 55 $\mathrm{MPa} \mathrm{m}^{1 / 2}$ and found that $\mathrm{da} / \mathrm{dN}$ in hydrogen increased with decreasing $\mathbf{f} . \mathrm{da} / \mathrm{dN}$ in hydrogen was 5 times higher than that in helium at $1 \mathrm{~Hz}$. However they conducted the test in helium at 1 $\mathrm{Hz}$ only, so that the effect of hydrogen on fatigue crack growth was not clear thoroughly.

Fracture surfaces. The fracture surfaces of the alloy without $\delta$ phase at $\mathrm{f}=5 \mathrm{~Hz}$ in 1.1 $\mathrm{MPa}$ argon and 19.7 MPa hydrogen are shown in Fig.9. The plate like fracture formed along the slip plane ${ }^{11)}$ was observed on the fracture surface both in argon (a) and hydrogen (b) at lower $\Delta \mathrm{K}$. Striations were observed on the fracture surface in $\operatorname{argon}$ (c) at $\Delta \mathrm{K}$ of $50 \mathrm{MPa}^{\circ} \mathrm{m}^{1 / 2}$. while brittle transgranular fracture was mainly surface in hydrogen (d).

The fracture surfaces of the alloy with $\delta$ phase at $f=5 \mathrm{~Hz}$ in $1.1 \mathrm{MPa}$ argon and 19.7 MPa hydrogen are shown in Fig. 10. The plate like fracture was also observed on the fracture 
surface both in argon (a) and hydrogen (b) at lower $\Delta \mathrm{K}$. Both striations and transgranular fracture were observed on the fracture surface in $\operatorname{argon}(\mathrm{c})$ at $\Delta \mathrm{K}$ of $50 \mathrm{MPa}^{1 / 2}$, while brittle transgranular fracture along the interfaces between $\delta$ phase and $\gamma$ matrix was mainly observed in hydrogen (d).

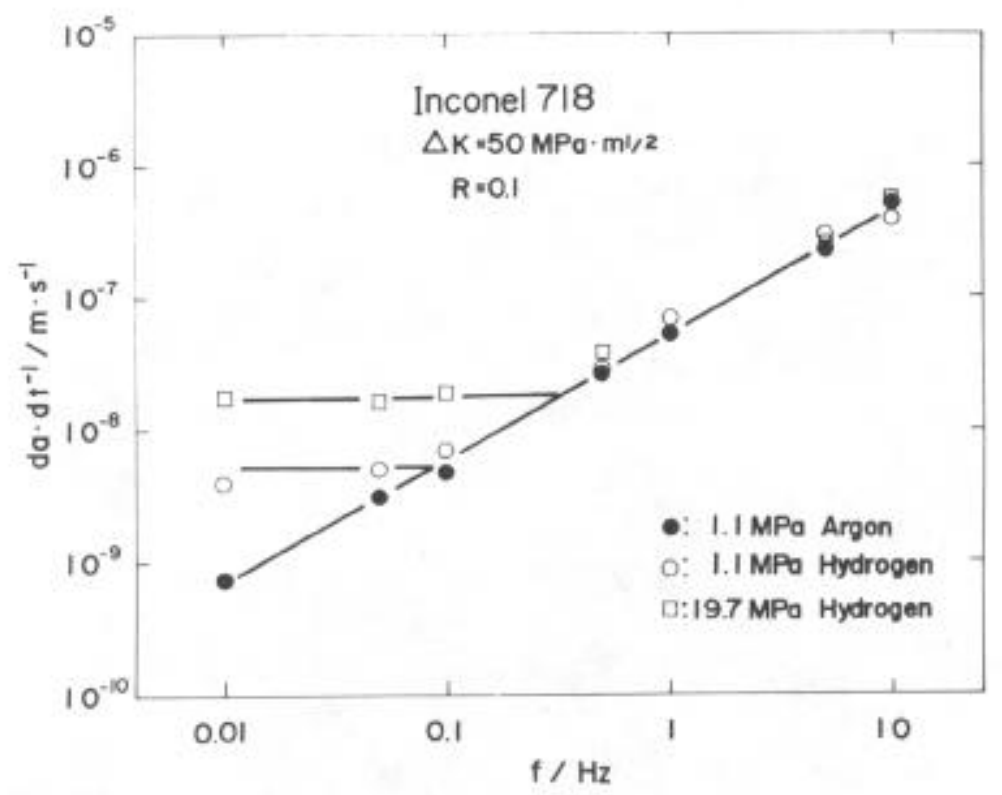

Fig.8 Effect of $\mathbf{f}$ on da/dt of Alloy 718 without $\delta$ phase in $1.1 \mathrm{MPa}$ argon, and 1.1 and 19.7 MPa hydrogen.
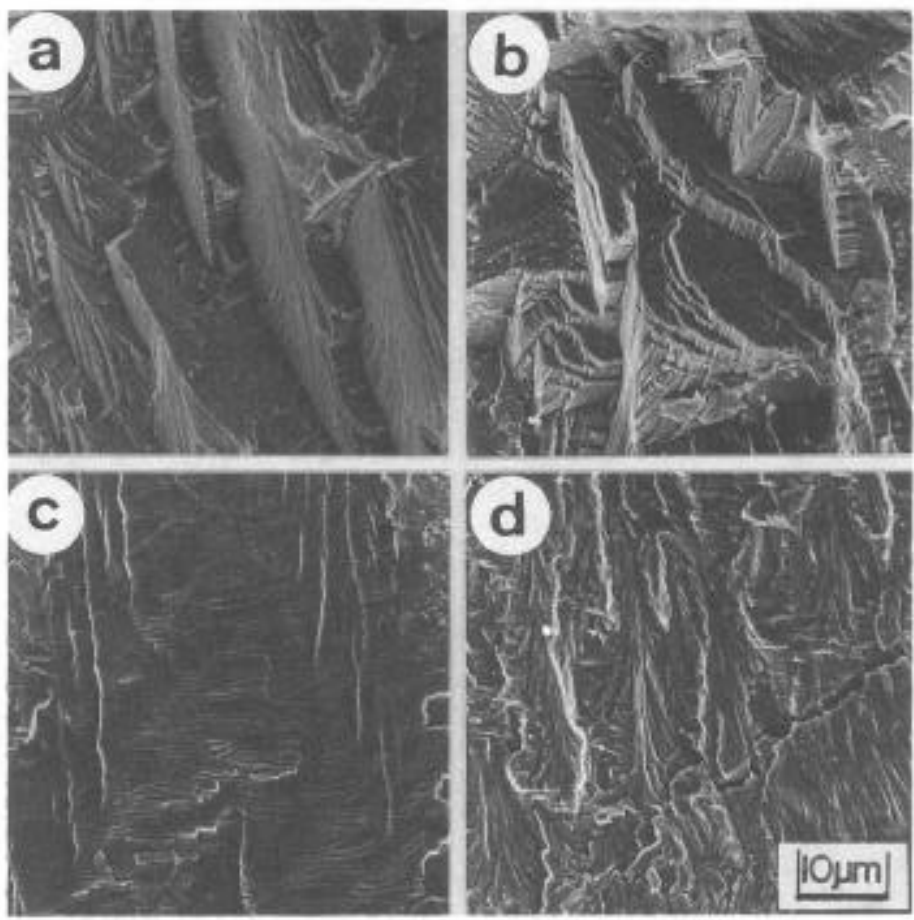

Fig.9 Fracture surfaces of Alloy 718 without $\delta$ phase at $\mathrm{f}=5 \mathrm{~Hz}$ in $1.1 \mathrm{MPa}$ argon and 19.7 MPa hydrogen. (a,b) : at $\Delta \mathrm{K}$ of $30 \mathrm{MPa}^{1 / 2}$, (c,d) : at $\Delta \mathrm{K}$ of $50 \mathrm{MPa}^{1 / 2,}$, $(\mathrm{a}, \mathrm{c}):$ in $1.1 \mathrm{MPa}$ argon, (b,d) $:$ in $19.7 \mathrm{MPa}$ hydrogen 
The effect of $\Delta \mathrm{K}$ on fracture mode of the alloy in argon and hydrogen is shown in Fig.11. On the fracture surface of the alloy without $\delta$ phase in argon, the plate like fracture decreased and the brittle transgranular fracture increased with increasing $\Delta \mathrm{K}$ below $\Delta \mathrm{K}$ of $35 \mathrm{MPa}^{1 / 2}$. Striations were observed above $\Delta \mathrm{K}$ of $35 \mathrm{MPa} \cdot \mathrm{m}^{1 / 2}$ and the dimple rupture was also observed above $\Delta \mathrm{K}$ of $63 \mathrm{MPa}^{1 / 2}$. While in hydrogen, the plate like fracture decreased with increasing

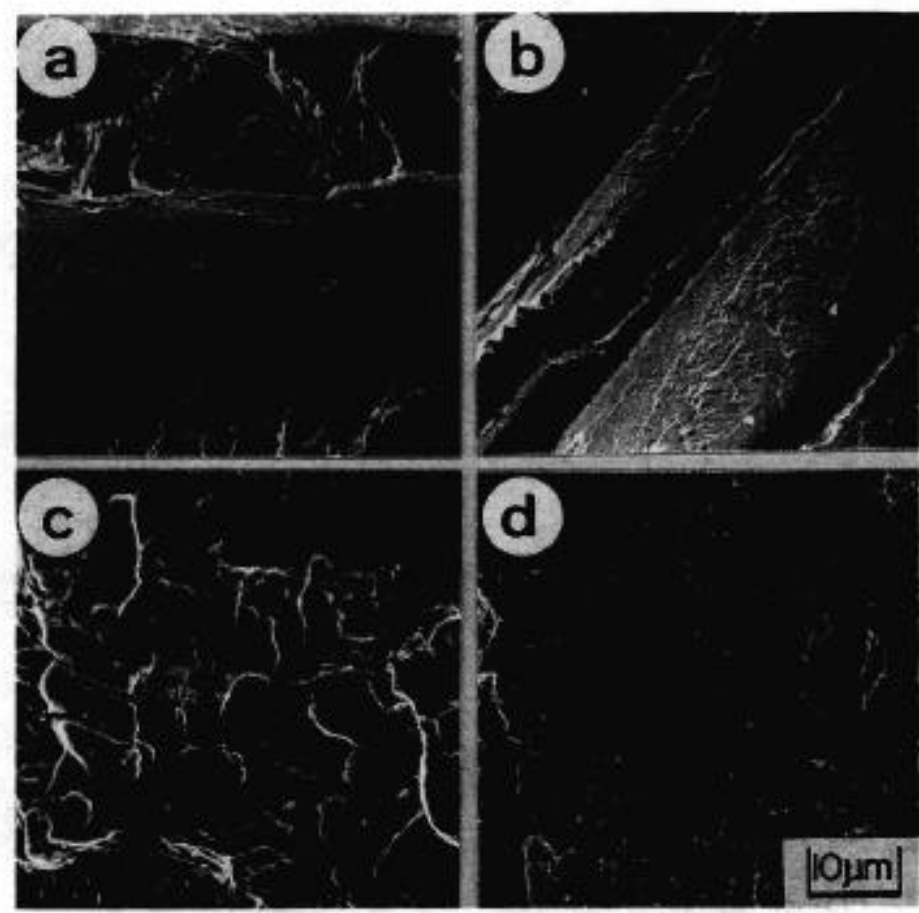

Fig.10 Fracture surfaces of Alloy 718 with $\delta$ phase at $\mathrm{f}=5 \mathrm{~Hz}$ in $1.1 \mathrm{MPa}$ argon and 19.7 $\mathrm{MPa}$ hydrogen. $(\mathrm{a}, \mathrm{b}):$ at $\Delta \mathrm{K}$ of $30 \mathrm{MPa}^{1 / 2}$, (c,d) : at $\Delta \mathrm{K}$ of $50 . \mathrm{MPa}^{\circ} \mathrm{m}^{1 / 2}$, $(\mathrm{a}, \mathrm{c}):$ in $1.1 \mathrm{MPa}$ argon, $(\mathrm{b}, \mathrm{d}):$ in $19.7 \mathrm{MPa}$ hydrogen

\section{Inconel 718}

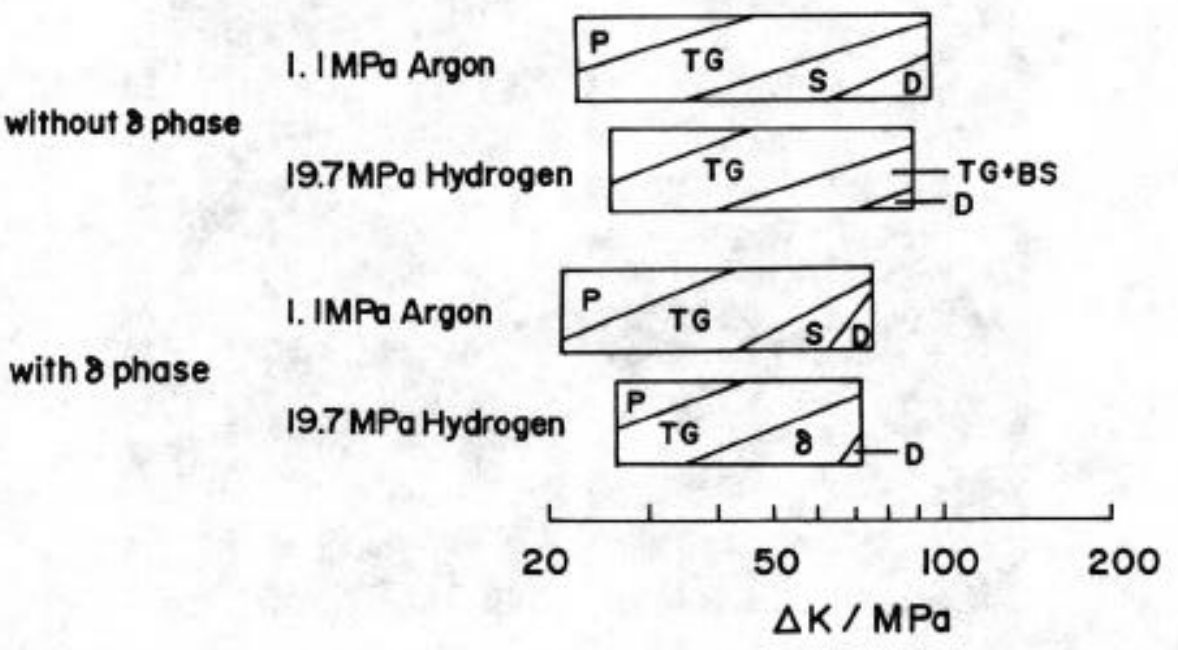

Fig.11 Effect of $\Delta \mathrm{K}$ on fracture mode of Alloy 718 in $1.1 \mathrm{MPa}$ hydrogen and $19.7 \mathrm{MPa}$ hydrogen. P : Plate like fracture, TG : Transgranular fracture, S : Striation, BS : Brittle striation, D : Dimple rupture, $\delta$ : Fracture along the $\delta$ phase. 
$\Delta \mathrm{K}$ below $\Delta \mathrm{K}$ of $47 \mathrm{MPa} \cdot \mathrm{m}^{1 / 2}$ as like as that in argon. The brittle transgranular fracture increased with increasing $\Delta \mathrm{K}$ below $47 \mathrm{MPa} \bullet \mathrm{m}^{1 / 2}$. The dimple rupture was also observed above $\Delta \mathrm{K}$ of $71 \mathrm{MP} \cdot \mathrm{m}^{1 / 2}$.

On the fracture surface of the alloy with $\delta$ phase in argon, the plate like fracture decreased and the brittle transgranular fracture increased with increasing the $\Delta \mathrm{K}$ below $\Delta \mathrm{K}$ of $44 \mathrm{MPa} \cdot \mathrm{m}^{1 / 2}$.

Striations werc observed above $\Delta \mathrm{K}$ of $44 \mathrm{MPa} \bullet \mathrm{m}^{1 / 2}$ and dimplc rupturc was also observed at $\Delta \mathrm{K}$ of $63 \mathrm{MPa}^{\bullet} \mathrm{m}^{1 / 2}$. While in hydrogen, the plate like fracture increased with increasing $\Delta \mathrm{K}$ below the $\Delta \mathrm{K}$ of $45 \mathrm{MPa}^{\bullet} \mathrm{m}^{1 / 2}$ as like as that in argon. The brittle transgranular fracture along the interface between $\delta$ phase and $\gamma$ matrix increased with increasing $\Delta \mathrm{K}$ above $35 \mathrm{MPa} \mathrm{m}^{1 / 2}$. The dimple rupture was also observed above $\Delta \mathrm{K}$ of $65 \mathrm{MPa} \cdot \mathrm{m}^{1 / 2}$.

On the basis of the results, hydrogen showed a marked effect on the fatigue crack growth above $\Delta \mathrm{K}$ which ductile striations were formed on the fracture surface in argon. It is well known that the tensile ductile striations have large plastic zone at the crack tip ${ }^{22,13,14)}$. It was found that hydrogen reduced the tensile ductility. As the crack growth occurred before the ductile striations were formed with large plastic deformation in hydrogen, so that the crack growth in hydrogen was higher than that in argon.

\section{Prevention of Hydrogen Assisted Fatigue Crack Growth}

The effect of gaseous inhibitors added to 1.1 MPa hydrogen on the fatigue crack growth of the alloy is shown Fig. 12. The inhibitive effect is expressed as

$[(\mathrm{da} / \mathrm{dN})$ Inhibitor - (da/dN)Argon $] /[(\mathrm{da} / \mathrm{dN}) \mathrm{Hydrogen}-(\mathrm{da} / \mathrm{dN}) \operatorname{Argon}]$

It was found that the addition of oxygen or carbon monoxide had much effect on preventing hydrogen assisted fatigue crack growth, but that of carbon dioxide had little effect. The authors ${ }^{15,16)}$ also found that oxygen or carbon monoxide showed much effect for steels.

According to the HEE theory ${ }^{19}$, hydrogen is adsorbed on the metal surface and penetrates into the metal body, and then hydrogen embrittlement comes about. It is expected that some compounds whose adsorption on metal surface is stronger than that of hydrogen would retard HEE. Adsorption of oxygen and carbon monoxide on metal are stronger than that of hydrogen ${ }^{18)}$, so that it is expected that their addition to hydrogen atmosphere retards hydrogen assisted fatigue crack growth.

On the other hand, it is found that water vapor accelerated the fatigue crack growth of the alloy. The authors ${ }^{16)}$ found that water vapor accelerated the fatigue crack growth of $2.25 \mathrm{Cr}-1 \mathrm{Mo}$ steel. The process is considered as follows; the chemical reaction between the metal and water vapor occurred on the fracture surfaces at the crack tip of the alloy, and then hydrogen came out. It is well known that hydrogen in nascent state ${ }^{19)}$ accelcrates hydrogen cmbrittlement. So, water vapor accelerated the fatigue crack growth.

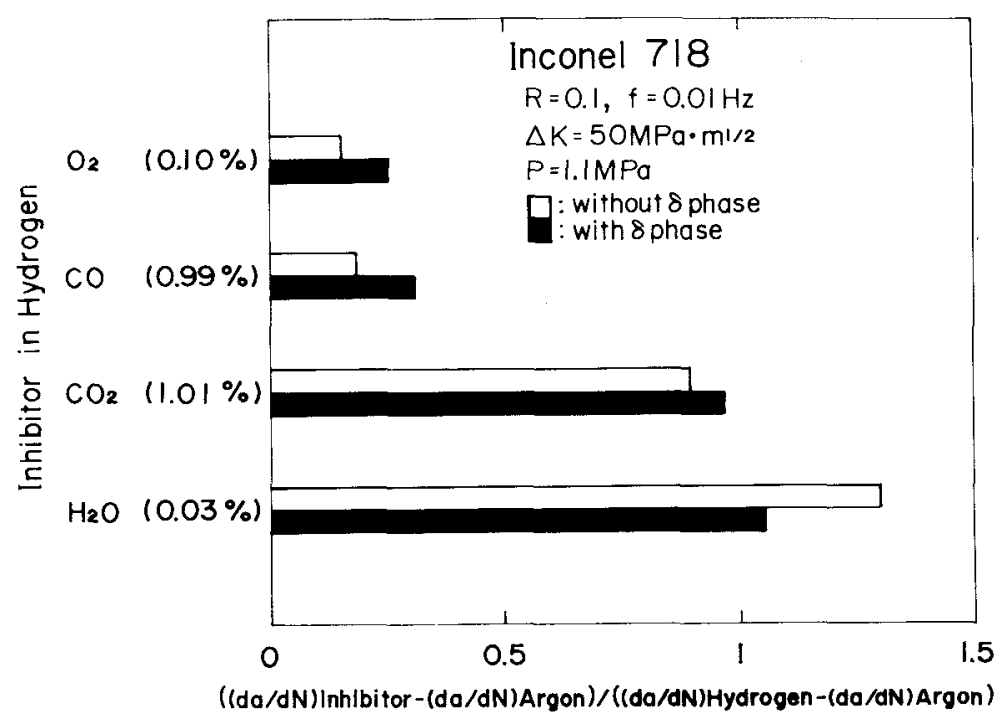

Fig.12 Effect of gaseous inhibitors added to 1.1 MPa hydrogen on fatigue crack growth of Alloy 718. 


\section{Conclusion}

Tensile and fatigue crack growth testings of Alloy 718 were conducted in high-pressure hydrogen of 1.1 MPa up to $19.7 \mathrm{MPa}$ and argon at room temperature up to $773 \mathrm{~K}$. Effects of heat treatments on HEE of the alloy were investigated. The effect of gaseous inhibitors added to hydrogen atmosphere on the fatigue crack growth of the alloy was also investigated to prevent hydrogen assisted fatigue crack growth. The results obtained are as follows;

(1) Effect of hydrogen on the tensile property increased with increasing $\delta$ phase and with decreasing testing temperature. HEE still occurred at $773 \mathrm{~K}$. The crack initiation occurred at carbide, and then the crack propagated along the interface between $\delta$ phase and $\gamma$ matrix of the alloy with $\delta$ phase or along the grain boundary of the alloy without $\delta$ phase.

(2) Hydrogen showed marked effect on the fatigue crack growth above the $\Delta \mathrm{K}$ which the striations were formed on the fracture surface in argon. Effect of hydrogen on the fatigue crack growth increased with decreasing the frequency of the cyclic loading. Delayed fracture was found predominantly in fatigue crack growth in hydrogen.

(3) It was observed that oxygen or carbon monoxide added to hydrogen atmosphere had much effect to prevent hydrogen assisted fatigue crack growth.

\section{Acknowledgement}

This study is supported financially by the Agency of Industrial Science and Technology, MITI, as New Energy R/D Grants in 1993.

\section{References}

1. Y.Yamada and E. Sogame, PISSTA787, 1987, 628.

2. J. A. Harris, Jr. and M. C. VanWanderham, NASA CR-124394, 1973.

3. R. J. Walter and W. T. Chandler, NASA CR 124110, 1973.

4. K. Rie, J. Ruge and W. Kohler, " Low-cycle Fatigue of Fe-Cr-Ni-Austenite and Ni-base Alloys in High Pressure Hydrogen," Proceedings JIMIS-2, Hydrogen in Metals, 1980, 529

5. K. Yokogawa S. Fukuyama, M. Mitsui and K. Kudo, "Pressure Vessel for Tensile Testing in High-Pressure Gases at Elevated Temperature," Rev. Sci. Instrum., Vol. 53, 1978, 50.

6. S. Fukuyama, K. Yokogawa and M. Araki, " Fatigue Crack Growth of AlSI4340 Steel in High Pressure Hydrogen at Room Temperature," J. Soc. Mater. Sci. Jpn (Japan), Vol.34, 1985, .

7. S. Fukuyama, K. Yokogawa, K. Kudo and M. Araki, " Fatigue Properties of Type 304 Stainless Steel in High Pressure Hydrogen at Room Temperature," Trans. Jpn. Inst. Met., Vol.2 6, 1985, 325.

8. H. Okamura, (Senkei Hakai Rikigaku Nyumon (Japan)), Baifukan, 1976, 220.

9. The Japan Society of Mechanical Engineering, (Standard Method of Test for Elastic-Plastic Fracture Toughness $\mathrm{J}_{\mathrm{IC}}$ (Japan)), JSME S001-1981, 1981.

10. R. P. Wei and G. W. Simmons, (Fatigue : Environment and Temperature Effects) Edited by John J. Burke and Volker Weiss, PLENUM PRESS, 1983, 59.

11. M. Clavel and A. Pineau, "Frequency and Wave-Form Effect on the Fatigue Crack Growth Behavior of Alloy 718 at $298 \mathrm{~K}$ and $823 \mathrm{~K}, "$ Met. Trans., Vol.9A, 1978, 471.

12. J. F. Knot1, Translated into Jpn. by H. Miyamoto, (Hakairikigaku no Kiso), Baifukan, 1977, 122.

13. R. Koterazawa, (Fractography To Sono Ouyou (Japan)), Nikkankogyo shinbunsha, 1981, 47.

14. H. Kobayashi, K. Hirono, H. Kayakabe and H. Nakazawa, "Influence of Hydrogen on Fracture Toughness of High Strength Steels," Sth International Conference of Fracture, Cannes, France, Fracture Research Advances IV, Vol.4, 1981, 1909.

15. S. Fukuyama, K. Yokogawa and M. Araki, "Fracture Toughness and Fatigue Crack Growth of AISI4340 Steel in High Pressure Hydrogen at Room Temperature," Proceedings of 6th International Conference on Pressure Vessel Technology, Beijing, China, Pergamon Press, Vol. 2, 1988, 539.

16. S. Fukuyama, K. Yokogawa, "Prevention of Hydrogen Environmental Assisted Crack Growth of 2.25Cr-1Mo Steel by Gaseous Inhibitors," Proceedings of 7th International Conference on Pressure Vessel Technology, Dusseldorf, German, VdTUV, Vol. 2, 1992, 914.

17. H. R. Gray, (Hydrogen Embrittlement Testing), ASTM STP543, American Society for Testing and Materials, 1974, 133.

18. Catalysis Soc. Jpn., (Shokubai Koza Vol. 1 (Japan)), Kodansha Scientific, 1985, 41.

19. Jpn. Inst. Metals, (Kinzoku Binran (Japan)), Marzen, 1971, 1625. 